Article

\title{
Sounding the Nonhuman in Joyce's "Sirens"
}

\author{
Rasheed Tazudeen
}

Department of English, University of Toronto, Toronto, ON M5R 2M8, Canada; r.tazudeen@gmail.com

Received: 10 June 2017; Accepted: 25 July 2017; Published: 24 August 2017

\begin{abstract}
This essay explores Joyce's attempt, in "Sirens", to give articulation to the sounds made by objects and nonhuman beings, with the ultimate goal of destabilizing the boundary separating the human voice (and other forms of human expression) from nonhuman sound. The episode itself can be read as a catalogue of sounds, nonhuman and human, that interact with one another in the absence of a qualitative standard of judgment that would separate the human voice from nonhuman sound, music from "noise", or conceptual language from sonic expression. Human characters in the episode become what Vike Martina Plock has called "soundboards", or resonating bodies through which the sounds of their material environment achieve expression. Additionally, human bodies are fragmented metonymically into their sounding body "parts" detached from the unity of the human subject, which allows for new forms of sonorous collaboration between sounding objects and sounding body parts. Nonhuman sounds persist in contrapuntal relation with the voices and sounds of the human characters (and their sounding body parts), a phenomenon which forces us to expand our conception of the fugal form of the episode to include nonhuman entities as collaborators, or "voices", within it. In this way, "Sirens" asks us to consider sound, and by extension music, not simply as the purely intentional product of a human consciousness, but also as a collective composition between human bodies (and body parts) and the sonic materials of their environment.
\end{abstract}

Keywords: James Joyce; modernism; sound studies; new materialism; posthumanism; music

"Man is only the vessel into which is poured what 'nature in general' wants to express."

-Anton Webern (Webern 1963, The Path to the New Music (Webern 1963))

"What is a word? The image of a nerve stimulus in sounds."

—Friedrich Nietzsche (Nietzsche 1968, “On Truth and Lie in an Extra-Moral Sense” (1968))

"Sea, wind, leaves, thunder, waters, cows lowing, the cattlemarket, cocks, hens don't crow, snakes hissss. There's music everywhere. Ruttledge's door: ee creaking. No, that's noise."

-James Joyce, Ulysses (1922) $)^{1}$

For an episode supposedly focused on music and musical structures, "Sirens" gives at least equal articulation to the sounds made by objects and nonhuman beings, such as the "noise" of the "ee creaking" door recalled by Bloom, with the ultimate goal of destabilizing the boundary separating the human voice (and other forms of human expression) from nonhuman sound. ${ }^{2}$ In this regard, Joyce's conception of the song (or the sound) of the Sirens seems to have been directly and indirectly

1 All citations of Ulysses are from the Hans Walter Gabler edition (New York: Vintage, 1986), with accompanying chapter and line number.

2 While the conception of "noise" I am drawing on will be fleshed out in further detail below, it is worth noting here that I am largely adopting R. Murray Schafer's four-part definition of "noise" in The Soundscape: Our Sonic Environment and the Tuning of the World. Schafer notes that "noise" is defined as "unwanted sound", "unmusical sound", "any loud 
influenced by the sounds and noises of nonhuman beings, and particularly by the sounds of objects, which will be the focus of this essay. During the episode's composition, according to Richard Ellmann, Joyce asked his friend and neighbor, the composer Philipp Jarnach, "about sirens, from those who inhabit Mediterranean rocks to those found in factories" (Ellmann 1982, p. 439). Joyce, it seems, was interested not only in the voices of the mythical Sirens, the singers who lead men to shipwreck with their "enchanting" song (a song that tells of "all the pains that the Greeks and Trojans once endured" and "all that comes to pass on the fertile earth", according to Homer), but also in the far more mundane sound of factory "sirens" that had become a staple of the industrialized world's soundscape by the early twentieth century (Homer 1986). Additionally, in Samuel Butler's translation of the Odyssey, one of the translations with which Joyce worked closely while composing Ulysses, Butler offers the following description of the Sirens:

The two Sirens doubtless were, as their name suggests, the whistling gusts, or avalanches of air that at times descend without a moment's warning from the two lofty mountains of Salinas—as also from all high points in the neighbourhood (Knowles 1986).

Butler's description disembodies the Sirens, moving away from the more explicitly erotic conception of the Sirens that tends to dominate contemporary understandings of them, and instead equates them with the "whistling gusts, or avalanches of air" descending from the mountains. In this way, the Sirens come to stand in for nonhuman sound, the sound of the whistling gusts of wind, which gets taken up in the many references to the sounds of wind in the "Sirens" episode, beginning with "A husky fifenote blew" (11.5) in the episode's introduction, continuing with the sound of "shepherd's pipes" ("Pwee little wee" [11.1241]) and ending with Bloom's flatulence at its close. ${ }^{3}$ More precisely, the Sirens are conceived in part as a particular sound ("whistling") that is the result of the collaborative interaction among a variety of nonhuman agents: the mountains, the air, and the wind that moves the air from the mountains to the earth to produce this sound. The "Sirens" of Ulysses, Lydia and Mina, are given to us in the first line of the episode as "bronze" and "gold" "hearing" the ringing of iron hoofs in the distance. We later learn that "bronze" and "gold" are metonyms regarding the color of their hair, but upon first encounter, the Sirens are given to us as the primary metals out of which objects (in Homer's time) were composed. Finally, the word for "Siren" ( $\sum \varepsilon\llcorner\varrho \eta \eta v)$ in the original Greek also refers to "a kind of solitary bee or wasp" and "a small singingbird", suggesting another nonhuman origin for the sounds of the Sirens: the buzzing and singing of wasps and birds. ${ }^{4}$

From mythical singing creatures to gusts of air descending from mountains to the primordial metals of bronze and gold to the sounds of insects and birds to modern industrial and urban noise, Joyce's conception of the Sirens gathers together several sources of nonhuman sound and puts them in contrapuntal relation with the voices and sounds of the characters of the episode. The episode itself can be read as a catalogue of sounds, nonhuman and human, that interact with one another in the

sound", or a "disturbance in any signaling system" (Schafer 1977, p. 182). For the purposes of this essay, I am particularly interested in the first two definitions: "unwanted sound" (which is inevitably a cultural construction) and "unmusical sound", which defines noise negatively as that which is not music. More specifically, according to Schafer (citing the 19th-century physicist Hermann Helmholtz), "noise" is "sound composed of nonperiodic vibrations (the rustling of leaves), by comparison with musical sounds, which consist of periodic vibrations" (p. 182). This is also a definition that aligns with Bloom's characterization of "noise", as the "ee creaking" of a door, in contrast with the "periodic vibrations" of sounds of nature and of human voices.

3 The emphasis on wind and wind instruments also touches on the motif of the Aeolian harp, which Joyce engages explicitly in the "Aeolus" episode of Ulysses as well as in the short story "Araby", from Dubliners (1914), in which the boy-narrator says regarding the object of desire, Mangan's sister, "But my body was like a harp and her words and gestures were like fingers running upon the wires" (Joyce 2006, p. 22). In the Classical tradition, taken up by Romantic poets such as Samuel Taylor Coleridge and Percy Bysshe Shelley, the Aeolian harp was figured as an instrument through which nature itself expresses itself through the medium of the human being playing it, turning the human being into a vessel or conduit for the expression of the natural world, rather than a composer who wills sounds into being.

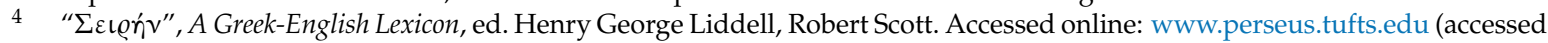
on 10 May 2017). 
absence of a qualitative standard of judgment that would separate the human voice from nonhuman sound, music from "noise", or conceptual language from sonic expression. Joyce's Sirens do not merely enchant the traveller through seductive voices and postures; rather, the temptation they offer is to bind human being, and the human voice, to nonhuman sound, and to remove the hierarchical distinction that customarily separates the two, immersing human being and human language into universe of sound. Josh Epstein notes that Joyce, largely as a result of his friendship with noise-music composer Georges Antheil, was interested in destabilizing the music/noise binary to allow forms of "noise" to achieve expression, as opposed to relegating "noise" to the realm of "unwanted sound". 5 Epstein writes:

[Joyce's] interest in Antheil exemplifies a remarkable curiosity, throughout his oeuvre, about the relative cultural potential of noise, music, and noisy music. In binding music and noise together, Joyce explores music and musically patterned language as rhetorical expressions engaged with a social context (Epstein 2011).

In Noise: The Political Economy of Music (1977), Jacques Attali argues that the music/noise binary is a culturally constructed one, and that music itself has its origins in "noise". Music can be thought of as "the organization of noise", and the coding of "noise" into particular kinds of music is at base a "tool for the creation or consolidation of a community, of a totality" (Attali 1985). It is appropriate to recall here the possible derivation of the word "siren" ( $\Sigma \varepsilon\llcorner\varrho \eta \eta v)$ from the word $\sigma \varepsilon\llcorner\varrho \dot{\alpha}$, which means "rope", but also a "binder" or "entangler", or "the one who grasps, or snares". 6 Joyce's Sirens entangle, or "bind", human and nonhuman modes of sound/noise with one another, and the episode itself is one where objects are allowed to sound alongside their human counterparts in a kind of collective, aleatory, and continually unfolding composition.

The 63-line introduction to "Sirens" (also referred to as an "overture") ${ }^{7}$ is a collection of sounds, and of language as sound, that opposes semantic meaning and instead asks us to engage with the sonorous particulars of each line. As we continue through the episode, we soon learn that the introduction serves in part as an index of significant sounds that occur during the chapter. Phrases like "Imperthnthn thnthnthn" (the bar assistant's sarcastic mockery of the phrase "impertinent insolence") and "Clapclap. Clipclap. Clappyclap" present language in terms of its aural (as opposed to its semantic) qualities (11.2, 11.28), and lines like "And a call, pure, long, and throbbing. Longindying call" (a reference to the sound of a tuning fork) and "Coin rang. Clock clacked" mark the sounding of nonhuman objects $(11.12,11.16)$. Later in the episode, as Bloom ponders the existence of "music everywhere", he makes a point to distinguish between the "music" of the natural world, and the "noise" of objects, such as the "ee creaking" of a door (11.968). Noise, in this sense, is what disrupts "music", which is conceived as a kind of harmonious and predictable progression of sound. However, this is precisely the separation that becomes undone throughout the episode, beginning with the introduction. The introduction, and "Sirens" as a whole, liberates noise from the "codes" in which it is contained, and allows noises to sound in their full sonorousness within the acoustic space of the episode. The codes in which noise is contained and organized into meaning include semantically meaningful language, the unified human subject, and traditional musical forms grounded in harmony, as I will argue throughout this essay. "Sirens" seduces us into a universe in which the customary separation between the sounds produced by humans (and the supposedly harmonious sounds of the natural world) and the inharmonious sounds or "noises" of objects is

5 I will discuss some of the relations between musical "noise" (as theorized and practiced by Modernist composers such as Arnold Schoenberg, Anton Webern, and Béla Bartók) and the "noise" of nonhumans (and nature generally) in Section 4 of this essay.

$6 \sum \varepsilon\llcorner\varrho n ́ v$, def. 1, and $\sigma \varepsilon\llcorner\varrho \alpha ́$, def. 2 and 3. Academic Dictionaries. Accessed online: http:/ / translate.deacademic.com (accessed on 10 May 2017).

7 See, for example, (Lawrence 1981; Warren 2013; Martin 2000-2001). 
undone, allowing for a broader conception of sound itself as a "binding" collaboration between human and nonhuman entities. The temptation of the Sirens, then, is the temptation of surrendering conscious speech and conceptual language to sonic expression and, by extension, creating new forms of sonorous collaboration with nonhumans.

\section{Binding}

The binding of human to nonhuman being occurs in a very literal sense, if we consider the scene when Lydia, one of the Sirens, commands George Lidwell (a bar patron) to "Listen!" to the sound of a "lovely shell", or "spiked and winding seahorn" that she "hold[s] . . to his ear" (11.925; 11.921-22; 11.930):

Ah, now he heard, she holding it to his ear. Hear! He heard. Wonderful. She held it to her own. And through the sifted light pale gold in contrast glided. To hear.

Tap.

Bloom through the bardoor saw a shell held at their ears. He heard more faintly that they heard, each for herself alone, then each for other, hearing the plash of waves, loudly, a silent roar.

Bronze by a weary gold, anear, afar, they listened.

Her ear too is a shell, the peeping lobe there.

$[\ldots]$

The sea they think they hear. Singing. A roar. The blood it is. Souse in the ear sometimes. Well, it's a sea. Corpuscle islands. (11.930-38; 945-46)

Lydia literally binds George to the object, demanding that he "hear" the sound that it emits. The object sounds, and the human characters here are agents only insofar as they have the capacity to "hear". Valérie Bénéjam notes that this sound is not actually produced by the sea contained within the shell that makes the sound (as the characters aside from Bloom believe), but by the fact that "the shell acts as a resonator amplifying the sound [of our surroundings] at specific frequencies, which are given by the shell's frequency and shape" (Bénéjam 2011). As such, the shell becomes a medium through which the external world can be heard, and through which one's surroundings are taken into the body. The object's sonic agency, like the human ear to which it is bound, emerges from its capacity to "amplify" the sounds of the external world for other hearing entities. If the "ear too is a shell", then hearing is a matter of taking into the body the sounds of the external world and refracting them through the vessel of the body. In this sense, the "sea" in question can be read as a metaphor for the external world itself that the patrons hear when they put the shell to their ears. In the moment of hearing, even visual images become auditory phenomena. When Bloom sees the shell and the listeners bound to it, this visual stimulus is immediately transmuted into Bloom hearing the barmaids "hearing": "He heard more faintly that they heard". The shell, as both a visual and an auditory stimulus, immerses the entities to which it is bound into a world of oceanic sound that encompasses their entire being. In Bloom's formulation, the ear is "souse[d]", or immersed in liquid, upon hearing the sounding shell, and the body is figured as another "sea" hearing the sea supposedly contained within the shell. Shell and ear, sea and body are united in what will later be termed the "endlessnessnessness" of sonic communion (11.750).

This, I want to argue, is the seduction of the Sirens: they threaten to souse human beings and human expression within a world of nonhuman sound, to the point where language itself is a material and sonic means of expression, rather than a conceptual one. In this vein, Vike Martina Plock (employing Hermann Helmholtz's theories of acoustic resonance) argues, in "Good Vibrations: 'Sirens,' Soundscapes, and Physiology", that the characters in "Sirens", along with many of the sounding objects in Sirens, become "soundboards" or "resonating bodies" for the sonic frequencies buzzing around them (Plock 2009). Rather than willing sound into being and projecting it into the external world, the characters (Bloom most of all) become resonating vessels that refract the sounds of the external 
world. ${ }^{8}$ The final sound of the chapter is, of course, the sound of Bloom's flatulence ("Pprrpffrrppffff" [11.1293]), which he links directly to the food he has consumed earlier in the day (or the outside that he taken into the inner space of his body). Characters such as Blazes Boylan are given to us through recurrent sonic motifs, such as the "jingle" of the carriage in which he arrives at the Ormond Hotel and the "creak[ing]" of his "smart tan shoes" across the bar floor $(11.19,11.761)$. The entire episode is punctuated by a recurring "Tap" that we later learn is the tapping of a blind man's cane reverberating through the collective auditory space of the episode, as heard in the seashell scene above.

One of the central "soundboards" of the episode is the chamber pot. For Bloom, the phrase "chamber music" (also the title of Joyce's first published book of poems) twins instrumental music with the recollected sound of Molly's urination into a chamber pot:

Chamber music. Could make a kind of pun on that. It is a kind of music I often thought when she. Acoustics that is. Tinkling. Empty vessels make most noise. Because the acoustics, the resonance changes according as the weight of the water is equal to the law of falling water. Like those rhapsodies of Liszt's, Hungarian, gipsyeyed.

Pearls. Drops. Rain. Diddleiddle addleaddle ooddleooddle. Hissss. Now. Maybe now. Before.

One rapped on a door, one tapped with a knock, did he knock Paul de Kock with a loud proud knocker with a cock carracarracarra cock. Cockcock.

Tap. $(11.979-989)^{9}$

"Music", here, is a matter of "acoustics", and the sounds produced by the interaction between human and nonhuman actors: Molly and the chamber pot, and the flow of urine that alters the resonant sound emerging from the pot, the "tinkling". Bloom makes an immediate connection between this resonating sound and Liszt's Hungarian Rhapsodies, and then to the sound of "rain". The ambiguous onomatopoetic phrase that follows: "Diddleiddle addleaddle ooddleooddle" can be attached equally to Liszt's rhapsodies or the sound of "falling water": read out loud, they resemble a set of running eighth-notes (either ascending or descending), the sound of urine plashing against the walls of a chamber pot, and the pattering of rain against the pavement. The traditional boundary between music and sound is unmade momentarily, but this is not a way of debasing instrumental music by comparing it to the sound of urine. Rather, it is a way of honoring the role of nonhuman sound, and the collaborative and aleatory production of sound by human and nonhuman actors, that serves as a basis for the production of what is called "music". According to Bloom's musings, the rhythms of raindrops, or of other kinds of "falling water", ground the rhythms of classical and other types of music.

8 In The Five Senses: A Philosophy of Mingled Bodies, Michel Serres suggests that the body itself begins its existence as a kind of resonating medium for the sounds around it. Serres writes:

[T] he whole body or organism raises a taut sculpture or statue of skin, vibrating to the voluminous sound, open-closed like a cylindrical drum, trapping what traps it. We hear through our skin and feet. We hear through our skull, abdomen and thorax. We hear through our muscles, nerves and tendons. Our body-box, strung tight, is covered head to toe with a tympanum. We live in noises and shouts, in sound waves just as much as in spaces, the organism is erected, anchors itself in space, a broad fold, a long braid, a half-full, half-empty box which echoes them. Plunged, drowned, submerged, tossed about, lost in infinite repercussions and reverberations and making sense of them through the body. Resonating within us: a column of air and water and solids, three-dimensional space, tissue and skin ... I am the home and the hearth of sound, hearing and voice all in one ... (Serres 2016, p. 141).

9 This origins of the pun stem from a bawdy remark by Joyce's friend Oliver Gogarty, who in 1904,

had brought Joyce to visit Jenny, an easy-going widow, and while they all drank porter Joyce read out his poems [from Chamber Music] ... The widow was pleased enough by this entertainment, but had to interrupt to withdraw behind a screen to a chamber pot. As the two young men listened, Gogarty cried out, "There's a critic for you!" Joyce had already accepted the title of Chamber Music which Stanislaus had suggested; and when Stanislaus heard the story from him, he remarked, "You can take it as a favorable omen." (Ellmann 1982, p. 154). 
In the phrase "chamber music", "music" is a collaborative product of acoustic interactions with and within the room, or "chamber", in which the sounds are contained. "Chamber music" gets its original name from the size of the room in which ensemble music is played, a more intimate setting than the concert hall. The acoustic properties of the room, in interaction with the sounds of the instruments, is what produces "chamber music", just as the acoustic properties of the chamber pot interact with the flow of water to produce the other version of "chamber music". Certain types of room allow for, and influence, the production of certain types of music. For example, Max Weber points to the material circumstances out of which Western harmonic music in Europe was generated. He asks, "Why was harmonic music developed from the almost universal polyphony of folk music only in Europe and only in a particular period, while everywhere else the rationalization of music took a different path ... ?"10 The answer Weber provides hinges largely on the "development of the piano, one of the most important technical elements in the development of modern music, and its spread among the bourgeoisie", a development which "had its roots in the specifically 'indoor' character of Northern European civilization". ${ }^{11}$

Similarly, Richard Cullen Rath provides a fascinating account of how changes in church acoustics from the medieval Catholic churches to the sixteenth-century post-Reformation churches influenced the development of musical forms. Medieval European churches were designed so that the priest was "invisible", his "voice never carr[ying] directly to listeners in the nave", but "reflected several more times before reaching any ears", turning the chancel itself into a kind of "beautifully executed, very large musical instrument", or "lute" (Rath 2012, p. 131). Sounds in these churches "bounded around echo upon echo rather than reaching the listener's ears all at once", creating an effect that "amplified the voice and enriched the tone, but at the cost of clarity" (Rath 2012, p. 132). Post-Reformation churches, on the other hand, emphasized "clarity of voice rather than fullness", and a space in which "the minister could be seen and heard by all" and in which the minister's voice would "amplif[y]", rather than "reverberate", dampening echoes and making the signal "nonreciprocal, from the pulpit to the congregation" (Rath 2012, p. 133). "These 'reformed' acoustics," Rath notes, "made it possible for one of the church's eighteenth-century cantors, Johann Sebastian Bach, to write intricate organ and voice music full of nuances that would have been lost in the old church" (Rath 2012, p. 133). In this sense, there is no separating "music" from the "chamber", or the material surroundings, with which it resonates in a mutual co-constitution of material and musical "form": all music, then, could be considered "chamber music".

In the paragraph following the "chamber music" musings, language seems to become a kind of pure sound, detached from referential meaning, as if the narrator of the episode has caught the sonorous contagion of the previous paragraph and loses all semblance of a designating function: "One rapped on a door, one tapped with a knock, did he knock Paul de Kock with a loud proud knocker with a cock carracarracarra cock. Cockcock" (11.968-88). The logic of connection is purely sonorous, based on rhyme (rapped/tapped, loud/proud, knock/Kock/knocker/cock) and similar rhythmic structures (rapped on a door/tapped with a knock, did he knock/Paul de Kock). Language, it seems, has returned to what Nietzsche has called its origins in "sound": "What is a word?" Nietzsche asks in "On Truth and Lie in an Extra-Moral Sense". "The image of a nerve stimulus in sounds". ${ }^{12}$

And yet something is designated in the midst of what seems to be nonsense syllabling: Bloom's anxiety about Blazes Boylan (who can be heard walking around the bar immediately prior to Bloom's thoughts on "chamber music") and the affair he is scheduled to have with Molly at some point during

10 Weber, "Value-judgments in Social Science", qtd. in Frederic Jameson, "Foreword" to Attali, Noise: The Political Economy of Music, p. 8.

11 Qtd. in (Weber, p. 8).

12 Although Nietzsche (1968) suggests an origin of language in the attempt to represent images and sounds with words, he also claims that sounds are only ever "metaphors" for the inaccessible things they try to name (p. 45). 
this day. ${ }^{13}$ These sounds/syllables take on a referential function as they resonate with Molly's joking, in "Calypso", about the name Paul de Kock, whom Bloom mentions to her as the author of a book on metempsychosis: the pun she made earlier in the day now becomes translated to Bloom's fears about the affair with Boylan and about Boylan's intrusion into the Blooms' home ("did he knock ... with a cock"). ${ }^{14}$ The transmission of Bloom's entirely real anxiety into the nonsense syllabling of a nursery rhyme, however, has the effect of distracting Bloom from the events (imagined and real) of the day. Sound becomes a means of distraction from the narrative, as Karen Lawrence argues in The Odyssey of Style in Ulysses: "[I]n 'Sirens,' the play of the language almost seems to interrupt the telling of the story" (Lawrence 1981). As a means of distraction, sound takes us away from the plot of the episode, from the dramas lived out by the human characters, and this is part of the seduction of the Sirens: to remove the characters (at least momentarily) from the world of interpersonal relations, and to connect (or bind) them, to the sounding entities around them, nonhuman and human alike.

Interpersonal relations themselves, in "Sirens", are mediated not by conscious interactions between individuals, but by the material body (and body parts) through which sound, including the voice, is produced. Bloom's response to Simon Dedalus's singing in the bar (along with the rest of the hearing patrons), for example, is registered through the body: "Braintipped, cheek touched with flame, they listened feeling that flow endearing flow over skin limbs human heart soul spine" (11.668-69). The voice is conceived as a "flow" that passes through the body, beginning with the "skin" and moving through the "heart" and "soul" to the "spine", this last being one of the primary centers of nerve sensations. When describing the production of this music, Joyce emphasizes the sounding body parts of the accompanist, Ben Dollard: "He plumped him Dollard on the stool. His gouty paws plumped chords. Plumped stopped abrupt" (11.451-52). And when Simon starts to sing: "The harping chords of prelude closed. A chord, longdrawn, expectant, drew a voice away", to which Richie remarks: "Si Dedalus' voice" (11.663-64, 667). When Bloom thinks about Simon's singing shortly afterwards, he marvels at "The human voice, two tiny silky chords, wonderful, more than all others" (with a pun on "cords" as organ and as musical "chords" [11.791-92]). Earlier, the mechanics of the piano are explored as the piano tuner goes to work on it: "He pressed ..., soft pedalling, a triple of keys to see the thicknesses of felt advancing, to hear the muffled hammerfall in action" (11.292-94). The production of music is a result of the material interaction between Dollard's "paws" "plumping the chords" to make the "muffled hammerfall" of the piano sound, Simon Dedalus's "voice" (or the vibration of his "tiny silky chords"), and the bodies against which it resonates, or Bloom's and the other patrons' "skin limbs human heart soul spine". This detachment of body parts from bodies, and the assignation of some kind of sonic agency to the body parts as opposed to the totalized individual, is by no means localized to this scene. Throughout the episode, characters are metonymized into their sounding body parts: Lydia's "wet lips" "speak", "titter", and "trill” (11.72; 11.76; 11.378), Boylan's "smart tan shoes creaked on the barfloor" (11.761), and, Bob Cowley's "twinkling fingers" (like Ben Dollard's) play the piano (11.958). Additionally, objects themselves, including Lydia's "shell" and Molly's chamber pot, sound alongside these body parts: the piano keys, like Cowley's fingers, "twinkle, all harpsichording"

13 Importantly, as Derek Attridge notes in "Language as Imitation: Jakobson, Joyce, and the Art of Onomatopoeia", it is ultimately impossible for language to achieve the condition of pure "sound" and extricate itself from its referential function, since words will always designate something other than themselves and relate to other semantic features of the language, even when they aspire to the condition of a kind of non-referential, pure sound, which Attridge names as "nonlexical onomatopoeia." "Nonlexical onomatopoeia" is defined as "the use of the phonetic characteristics of the language to imitate a sound without any attempt to produce recognizable verbal structures, even those of traditional 'onomatopoeic' words" (Attridge 1984, p. 1120). What Joyce's use of onomatopoeic sounds in "Sirens" gives us, according to Attridge, is a heightened experience of the referentiality of language as it attaches meanings to words. In other words, Joyce's use of onomatopoeia is not "mimetic", but a site for the generation of new connective possibilities between sonic signifier and referent (Attridge 1984, p. 1133).

14 And looking forward to "Penelope", this same sonic signature of Boylan's knock modulates into "tattarrattat" in Molly's mind: "I was just beginning to yawn with nerves thinking he was trying to make a fool out of me when I knew his tattarrattat at the door he must have been a bit late" (U 18.341-343). 
(11.324), a "coin rang", and later, "clanged" (11.16, 11.383) a tuning fork "throbbed, pure, purer, softly and softlier, its buzzing prongs" (11.315-16) and a door creaks "ee" (11.965).

One of the effects of detaching body parts from bodies in this way, as Derek Attridge argues, is to destabilize the idea of a totalized human subject. When "fingers" play a piano, instead of "Ben Dollard" playing a piano, for example, the human subject is no longer the privileged locus of expression. As Attridge remarks in "Joyce's Lipspeech: Syntax and the Subject in 'Sirens,' " what is "worrying" in cases like this

is that the grammatical subject is no longer a human subject: syntax and our sense of the world have ceased to coincide. Even when the activity is fully localizable within the conscious mind, we prefer to specify the individual as a mental and physical unity: She thought hard, not Her mind thought hard. The totalizing pronoun "she" satisfies us by providing a fully constituted human subject, answerable to the rules and norms of the society which confers identity upon all subjects; "her mind" disturbs us as an isolated and ungovernable potency (Attridge 1986, p. 59).

Mind is separated from body, and the parts of the body take on an "ungovernable potency". For Attridge, the fragmentation of the body into parts opens up the space for eroticism, which depends upon the fetishization of certain body parts, as opposed to the religious version of the body, which conceives of the body, mind, and soul as a single, unified entity that cannot be corrupted by fragmentation. However, what also emerges through the fragmentation of the body, I want to argue, is the opening up of a space for the mutual interaction between human and nonhuman sound. If sound doesn't emerge from a singular body united with a conscious mind, but from the fragmented material parts of the body, then there is little conceptual difference between a sounding body part and a sounding material object, such as the piano keys, the tuner, the coin, and the shell. This is partly what informs R. Murray Schafer's concept of the "soundscape", which he defines as "the sonic environment", composed of all the noises that occur within an environment, without differentiation between human and nonhuman sound. As Schafer declares in the Introduction to The Soundscape: "Today all sounds belong to a continuous field of possibilities lying within the comprehensive dominion of music. Behold the new orchestra: the sonic universe! And the musicians: anyone and anything that sounds!" (p. 5). "Sirens" enact a sonic universe in which nonhuman objects can sound alongside the sounding parts of the human body, giving rise to new forms of acoustic space rooted in the collaboration between human and nonhuman sound.

\section{2. "fuga per canonem"}

This "binding" of music and noise also has bearing on questions of musical form, and most specifically, on the "fugal" form of the "Sirens" episode. Joyce famously remarked in a letter to Harriet Shaw Weaver that the episode is structured as a "fuga per canonem" or a fugue in the form of a canon (Joyce 1975, p. 242), leading generations of critics to debate whether the episode actually fulfills the criteria of the fugal form or if these words were meant more as a suggestive allusion rather than a strict statement about the episode's formal structure. ${ }^{15}$ In a basic sense, a fugue (derived from the Latin, fugere: to flee) is a piece for two or more voices in which a musical theme is introduced (subject) and then imitated but modified by a second voice (answer). As the piece develops, the two (or more) voices modulate through different keys, and finally, rejoin the opening key of the subject in harmonic unity as the piece concludes. The question of whether "Sirens" actually meets these criteria is still, nearly a century after its publication, unresolved. However, Nadya Zimmerman's analysis, in "Musical Form as Narrator: The Fugue of the Sirens in James Joyce's Ulysses", provides what is to my mind the most compelling argument regarding this question, and regarding the musical form of "Sirens" in

15 See, for example, (Levin 1965; Lees 1984; Knowles 1986; Ordway 2007; Zimmerman 2002; Brown 2007; Witen 2010, 2018). 
general: because there is "no accepted formula for translating a musical form into written language, each scholar will have his or her own standards by which to judge whether the musical form in 'Sirens' is a successful translation" (Zimmerman 2002, p. 109). Zimmerman broadens the somewhat limited question of success vs. failure regarding the episode's conformity with the fugal structure to think about the implications of using "musical form in prose" for questions of "narrative and temporality" and to explore how the form of the fugue can be used to express the simultaneity of narrative events (p. 109). In this way, the episode is at least in part meant to be read as we would read a musical score: both horizontally, as the piece unfolds in time, and vertically, as different notes/events occur simultaneously throughout the piece. While it is ultimately impossible to express simultaneity in the medium of writing, a medium which necessarily must be perceived in time, Joyce nonetheless simulates simultaneity by describing the same temporal sequence from multiple perspectives, a motif that David Herman argues bears a strong resemblance to Arnold Schoenberg's experimentations with the vertical polyphony of the fugue in twelve-tone composition (Herman 1994).

For example, when Lydia and Mina are hearing the viceregal hoofs go by, Bloom is simultaneously walking by "Moulang's pipes bearing in his breast the sweets of sin", even though the description of Bloom occurs twenty lines after the description of Lydia and Mina (11.86-87). Zimmerman writes:

Bloom is walking by the Moulang pipes at the exact moment that the Sirens are gossiping in the bar. By keeping a strong sense of time in mind, the reader can sense the simultaneity of events that are separated on the page. In a fugue or canon, if two or more lines of music in different voices occur simultaneously, they are said to be in counterpoint with each other. Hence, as Bloom walks by the Moulang pipes, we can say that he is in counterpoint with the conversation between the Sirens in the bar, because these two events are happening at the same time in the plot (Zimmerman 2002, p. 112).

Joyce remarked in the same letter to Weaver that the episode is composed of eight voices, or "eight parts", which Zimmerman names as the eight main characters of the episode: Lydia and Mina, Bloom, Pat the waiter, Simon Dedalus, Boylan, Lenehan, the blind tuner, and Ben Dollard (Joyce 1975, p. 242). These, according to Zimmerman, are the eight voices in counterpoint with one another throughout the episode. The subject of whether or not these are the eight central voices, or whether there are more than eight voices, is an ongoing debate, to which my only contribution here is to consider the possibility that these "parts" or voices, whether they number eight or more, may also include the voices/sounds of nonhumans in contrapuntal relation with the voices and sounds of the episode's human characters. ${ }^{16}$ Considering Joyce's interest in the graphic resemblance of the number 8 to the infinity symbol $(\infty)$, we could think of "eight" metaphorically as an expression of the infinite, ceaselessly looping "endlessnessnessness" of sonic communion between human and nonhuman sounding and resonating bodies and parts.

The form of the fugue offers a space in which multiple, discrete parts or voices can communicate with one another, and in early versions of fugal form, this communion was meant to produce an overall harmony analogous to the idea of a stable and unified subject. In the seventeenth and eighteenth centuries, according to Zimmerman,

fugal forms served as musical analogues to the notion of the centered Self: fugue narrated a quality of "subjective becoming", in which heterogeneous elements of self come together as an autonomous whole. Joyce, however, employs a fugal structure to question autonomy and simulates simultaneity in order to reveal a multi-vocal interiority (Zimmerman 2002, p. 109).

The only modification I would make to this compelling argument is that rather than reveal a "multi-vocal interiority", what "Sirens" actually does with its uses of (and departures from) the fugal

16 See the articles referenced in footnote 15, especially Lees, Zimmerman, Brown, and Witen. 
form is to provide a "multi-sonorous exteriority", in which the contrapuntal relations do not take place exclusively between the voices and sounds of the human characters, but also between humans and sounding objects, and between and among objects themselves. As Lydia and Mina are gossiping in the bar, and as Bloom is walking by Moulang's pipes, a third "voice" or "sound" joins the contrapuntal unfolding of the melody, and this is the "steelyringing" of the "viceregal hoofs", the sound the opens the episode, both in the introduction and in the episode proper, and provides a bridge between the end of "Wandering Rocks" and the beginning of "Sirens".

Mina and Lydia don't provide a "voice" at the beginning, but merely register the presence of another voice/sound: the "viceregal hoofs ... ringing steel". Even more particularly, it is not Mina and Lydia as subjects that hear the hoofs, but their "head[s]" that perform the hearing action ("Bronze by gold, miss Douce's head by miss Kennedy's head, over the crossblind of the Ormond bar heard the viceregal hoofs go by, ringing steel" [11.64-65]). The individual is fragmented into its sounding (and in this case, its hearing) parts, and the sonic dialogue here is not just between Bloom and the Sirens, but between the viceregal hoofs, the "heads" of Mina and Lydia, Bloom passing by Moulang's pipes, and the bar assistant, metonymized as "boots", who approaches Mina and Lydia at this point and "bang[s] on the counter his tray of clattering china" (11.64, 11.89-90). In other words, this section of the piece consists of at least four voices, and not just two.

The introduction of "Sirens" is completely alien to the fugal form. ${ }^{17}$ This collection of sounds is precisely what cannot be integrated easily into the musical form of the episode. ${ }^{18}$ The sounds are without harmony, without logical connection to one another or to the narrative events of the episode (at least upon first reading), and without a clear reason for their existence at the beginning of the episode. These sounds are both representative of the episode's events and detached from them: they become distractions from the narrative, from the relations between characters, and from the musical form of the episode itself, if we take Joyce's "fuga per canonem" remark at its word. Further, this fragmentation of the episode's events into discrete sonic units performatively enacts both the fragmentation of individual beings into sounding body parts and the fragmentation of the "unified self" proper to fugal form. In other words, the introduction becomes a kind of body fragmented into sounding parts, which lays the ground for the metonymization of characters into body parts throughout the remainder of the episode. But while the traditional fugal structure is based on a reconciliation of the self through the harmonic resolution of the different melodic lines, "Sirens" refuses to reconcile the fragmentation it unleashes upon bodies, upon language, and upon musical form itself. If it is a fugue, it is a broken one, beginning with an alien formal element in the introduction, and full of the interjections of object sound and urban noise that interrupt the clear voicing of melodies and prevent a harmonic resolution from emerging. Further, the voices themselves are bound up with these nonhuman sounds, and music becomes a collaboration between sounding human and nonhuman entities, body parts and objects alike. The fiction of a "unified self" through harmonic resolution is precisely what seems be coming unwound in "Sirens".

The fugue, however, is a form flexible enough to contain the variations and the multi-sonorous soundings of objects and their interactions with the human voice. It is a form that, as Theodor Adorno argues, does not serve as a kind of neutral container for harmonious voices that fit seamlessly together, but one that is continually remade by the voices themselves. Adorno writes, in Philosophy of New Music (1947):

What the schools call good counterpoint-namely, lines that are smooth and autonomously meaningful but do not intrusively overshadow the main voice, or harmonically flawless movement and adroit concatenation of heterogeneous lines by the prudent addition of

17 Lees argues that the introduction is itself a fugue, but has to make some wild conceptual leaps to get here, eventually attempting to pattern the fragments of sound in the overture into musical notation in the form of the fugue, which seems to be something beyond what the text is actually doing. See (Lees 1984).

18 Scott Ordway offers an interesting analysis of how the presence of the introductory "overture" makes the form of the episode more akin to the sonata than the fugue. See (Ordway 2007), "A Dominant Boylan." 
a well-fitted part-gives only the thinnest decoction of the idea of counterpoint by misusing it as a recipe. The aim of counterpoint was not the felicitous and complementary addition of voices but rather the organization of music in such a fashion that it has by necessity need for each voice contained in it and that each voice, each note, precisely fulfills its function in the texture. This texture must be so conceived that the relationship among the voices dictates the course of the entire piece, and ultimately the form (Adorno 2006, p. 74).

The form of the fugue, in Adorno's analysis, is not based simply on "good counterpoint", but by the "necessity" of each voice, and each "note", as a contribution to the texture of the piece, with the ultimate suggestion that the "form" does not pre-exist the content of the voices, but itself is determined by the "relationship" between these voices. This follows partially from Adorno's earlier suggestion, in the same work, that "all forms of music ... are sedimented contents" (Adorno 2006, p. 37). This conception of the fugue also borrows from the compositional strategies of Arnold Schoenberg, whose innovation of serial composition, or the twelve-tone row, was partially rooted in a modern re-engagement with fugal form, and specifically, with the capacity of the fugue to allow the content of a piece to continually reshape and redefine its form, as analyzed brilliantly by David Herman (Herman 1994). Regarding twelve-tone technique, Schoenberg writes in "Composition with Twelve Tones" (1941):

The two-or-more dimensional space in which ideas are presented is a unit. Though the elements of these ideas appear separate and independent to the eye and the ear, they reveal their true meaning only through their cooperation, even as no single word alone can express a thought without relation to other words ... The elements of a musical idea are partly incorporated in the horizontal plane as successive sounds, and partly in the vertical plane as simultaneous sounds. The mutual relation of tones regulates the succession of intervals as well as their association into harmonies ... (Schoenberg 1975).

With this more capacious understanding of the fugue in mind, we can begin to see how "Sirens" attempts to complicate fugal form from within by entangling "voice" with "sound", by refusing the formal exclusion of noise from the piece, and by rejecting the construction of a unified self out of the fragmented body parts and inharmonious sounds of the episode, ultimately producing new modes of relation between human and nonhuman sounding entities. One way to think about the presence of the introduction in "Sirens" is as a self-contained sonic unit that the remainder of the episode merely unfolds in time. The sounds, in other words, pre-exist the narrative events, and the narrative events exist only as a means of actualizing the development of these sounds in some kind of temporal sequence. If we look at the sound of the viceregal cavalcade of the first line, it first appears as "[the barmaids] heard the hoofirons, steelyringing", then in the first line of the episode proper, "heard the viceregal hoofs go by, steelyringing", and further on, "heard steelhoofs ringhoof ringsteel" $(11.1,11.64-65,11.113)$. The sound of the hoofs is modulated, perhaps through what we might call the literary analogue of different melodic keys, as it is heard by the barmaids. Their hearing (or the hearing of their "head[s]") is a means by which the multivalent sound of the hoofs is able to realize itself in its full sonorousness. Like the vertical sounding of a chord in a fugue, it occurs in a single instant of time, but its full articulation can only unfold horizontally across the space of the literary text. As Zimmerman notes, however, "Sirens" is a text that experiments with the production of simultaneity across the space of a horizontally perceived medium. How do we hear all of the multivalent properties of a single sound, the sound of the viceregal hoofs in this case, when it only occurs in a single instant? "Sirens" answers this question by performatively enacting the hearing of the sound in three different, but simultaneously occurring variations, all of which require a hearing ear in order to become actualized.

A similar phenomenon occurs with the sound of the tuning fork, which is also given to us in the overture, and then again as a kind of developmental variation in the body of the episode. First: "And a call, pure, long and throbbing. Longindying call" (11.12). And when it recurs: "From the saloon a call came, long in dying. That was a tuningfork the tuner had that he forgot that he now struck. 
A call again. That he now poised that it now throbbed. You hear? It throbbed, pure, purer, softly and softlier, its buzzing prongs. Longer in dying call" (11.313-16). The decontextualized sound is given an agent, and the sound itself varies from "pure, long and throbbing" and "Longindying call" to "throbbed, pure, purer, softly and softlier, its buzzing prongs" and "Longer in dying call". Like the seashell, the tuning fork is both a hearing and a sounding object, picking up the vibrations of the sounds around it (a way of "hearing" the piano and other sonorous entities surrounding it), and transmuting those vibrations into a "[1]ongindying" and "[1]longer in dying" "call". We are forced to attune to the materiality of the sound ("You hear?"), and specifically, to the decay of the sound (a term for the rate at which a sound falls into silence): the addition of "longer in dying" to the word "longindying" performs an extension of the decay, giving us two different variations simultaneously. The same goes for "pure, purer, softly, and softlier", which is a way of continually unfolding the sensuous particulars of the tuning fork's "call" through descriptive words that are redundant but for the material extension of sound ("purer", "softlier") that they performatively produce. Finally, the question "You hear?" emerges from an unknown speaker, but the injunction is the same as the one given by Lydia to George, when she commands him to "Hear!" Human hearing becomes a means of registering the polyvalent sounds of objects, and a means of expressing these sounds within the horizontally perceived medium of writing. In this reading, the characters become a means through which to develop the unfolding of the sonic themes of the overture, a means through which these themes can become fully realized as sound, and as music: the human body is a soundboard, or a resonating body, through which the sonic material of the universe achieves expression. ${ }^{19}$ As Anton Webern, following Goethe, writes in The Path to the New Music (1932-1933): "Man is only the vessel into which is poured what 'nature in general' wants to express" (Webern 1963).

\section{3. "It buzz, it twanged" (11.796)}

In The Soundscape, Schafer gives two accounts from Greek mythology about the origin of music, which he claims are the "two basic ideas of what music is or ought to be":

Pindar's twelfth Pythian Ode tells how the art of aulos playing was invented by Athena when, after the beheading of Medusa, she was touched by the heart-rending cries of Medusa's sisters and created a special nomos in their honor. In a Homeric hymn to Hermes an alternative origin is mentioned. The lyre is said to have been invented by Hermes when he surmised that the shell of the turtle, if used as a body of resonance, could produce sound.

In the first of these myths music arises as subjective emotion; in the second, it arises with the discovery of sonic properties in the materials of the universe. These are the cornerstones on which all subsequent theories of music are founded (Schafer 1977, p. 6 ).

This tension between the crying voice/aulos (pipes) and the resonating shell, or the sound of subjective emotion and the sonic materiality of the universe, maps onto "Sirens" as well. As Bloom muses on the affective properties of the human voice, he also reflects on the very materiality of that voice, as the "vibration" of "two tiny silky chords". And as he experiences Simon Dedalus's singing of an aria from Friedrich von Flotow's opera $M^{\prime}$ Appari (1846), which unites all of the bar patrons in a kind of sympathetic communion with his voice, he tries to tease out how music (or perhaps, more precisely, sound) comes to have the effect that it does upon listeners:

Words? Music? No: it's what's behind.

19 Daniel Ferrer points out that in an early draft of "Sirens", Bloom, as a "character" and as a "point of view" is completely absent for the first ten pages (58). In these first ten pages, there is "no monologue at all" and no "other form of stream-of-consciousness" and "very little subjectivity", as the dialogue, sounds (of the tuning fork, of singing, of a tinkling dinner bell, etc.), and third-person narration dominate (58). What this early draft seems to suggest is the de-centering of Bloom's consciousness as a means of engagement with the world, in favor of more collaborative forms of relation between characters and sounds. See (Ferrer 2001). 
Bloom looped, unlooped, noded, disnoded. (11.703-4)

The "behind" in this phrase can be read in a number of ways: as the emotional content underlying musical expression, as a statement about the "absolute[] musical structures" underlying all expression, as David Herman argues, or as the material entities behind the production of sound, or even as a gross pun on Bloom's flatulence at the close of the episode (Herman 1994, p. 478). At stake here, it seems, is the question of whether music should be thought of as the product of subjective emotion, or of the objective properties of the universe that sound through the human as a soundboard, or resonating body, that allows the noisy expression of objects to manifest itself. As Bloom is thinking about "what's behind" and listening to Simon's singing, he is also playing with an elastic band, his own kind of "lyre". About twenty lines earlier:

Love that is singing: love's old sweet song. Bloom unwound slowly the elastic band of his packet. Love's old sweet sonnez la gold. Bloom wound a skein round four forkfingers, stretched it, relaxed, and wound it round his troubled double, fourfold, in octave, gyved them fast. (11.681-84)

As he listens to the vibrating of Simon's "two tiny silky" vocal cords, he manufactures a sounding instrument of his own in the form of this elastic band that he winds around his fingers. The sounding object becomes "bound" with Bloom's fingers and hands. This is commonly read as the moment corresponding to Odysseus binding himself against the mast of his ship in order to protect himself from the seduction of the Sirens, whose song threatens to remove his sense of self-preservation against the temptations of aesthetic pleasure. In this moment, as this interpretation goes, Bloom is protecting himself (or at least distracting himself) from the knowledge of Boylan's affair with Molly, which is supposedly occurring at this very moment in time, by fiddling with the elastic band. However, we could also read this as the moment of Bloom's attempt to resist the seductions of the sonic universe itself, to resist becoming absorbed into a world of pure sound, in which the human body is a fragmented set of noisy parts that sound alongside the other nonhuman entities by which it is surrounded. By asserting himself as a kind of creator of sound, a composer who thinks in terms of what he later calls the "musemathematic[ ]" categories of "double, fourfold" and "octave", his "binding" enacts a sense of self-preservation against the temptations of sound. Bloom appears here as a fully formed subject and all of the actions are given as manifestations of his conscious will: "Bloom wound a skein round four forkfingers" (not "his fingers wound the elastic band", for example).

It is important to note that Hermes' sublimation of the sound of the resonating turtle shell into the lyre is also an artistic act of converting the sonorousness of material objects into an idea of the fundamental "harmony of the universe". In Schafer's account, the music of the lyre represents the "Apollonian" ideal, as

external sound, God-sent to remind us of the harmony of the universe. In the Apollonian view music is exact, serene, mathematical, associated with transcendental visions of Utopia and the Harmony of the Spheres ... It is the basis of Pythagoaras's speculations and those of medieval theorists ... , as well as of Schoenberg's twelve-note method of composition. Its methods of exposition are number theories. It seeks to harmonize the world through acoustic design (Schafer 1977, p. 6).

Similarly, after playing with the elastic band for some time, Bloom thinks about the "mathematical" construction of all music:

Numbers it is. All music when you come to think. Two multiplied by two divided by half is one. Vibrations: chords those are. One plus two plus six is seven. Do anything you like with figures juggling. Always find out this is equal to that ... Musemathematics. And you think you're listening to the etherial. But suppose you said it like: Martha, seven times nine minus $x$ is thirtyfive thousand. Fall quite flat. It's on account of the sounds it is. (11.830-35) 
Music, in Bloom's reading here, is a matter of manipulating "mathematical" figures, which is the same way he conceives of his engagement with the rubber band, which he stretches in accordance with "musemathematic" principles: "doubled, fourfold, in octave".

However, the description of Bloom actually playing this improvised "lyre" complicates this idea of mastery over the instruments of sonic expression. As he plucks the band while listening to the singing:

Bloom ungyved his crisscrossed hands and with slack fingers plucked the slender catgut thong. He drew and plucked. It buzz, it twanged. While Goulding talked of Barraclough's voice production, while Tom Kernan, harking back in a retrospective sort of arrangement talked to listening Father Cowley, who played a voluntary, who nodded as he played. While big Ben Dollard talked with Simon Dedalus, who nodded as he smoked, who smoked. (11.795-801)

Here the sound of the elastic band separates from Bloom's complete control, and sound (or music) instead becomes a kind of collaboration between Bloom and the band: "He drew and plucked. It buzz, it twanged." Cause and effect (or action and sound) are momentarily separated, broken across two sentences with identical rhythmic meter, which requires the breaking of grammatical sense in order for the second sentence to fit. The "buzz" and "twang" emerge from the instrument, and this is a sound that persists in a vertical (or simultaneous) relation with all of the other sounds achieving expression in the bar: Goulding talking, Father Cowley playing a voluntary, Dollard talking, etc. The "while" that begins each clause in the next sentence suggests the simultaneity of all of these sounds, requiring us to think them together as a single polyphonic statement, with the elastic band as one of the fugal "voices".

There is a further ambiguity in the earlier description of Bloom as he ponders "what's behind" "words" and "music": "Bloom looped, unlooped, noded, disnoded." In one sense, this describes Bloom "loop[ing]" the elastic band into different configurations. But in another sense, we can look at it as Bloom himself turning into a kind of sounding object here, as he himself "loops, unloops", or becomes twisted into a loop with the elastic band, and then twisted out of it (or "unloop[ed]"). This image of "looping and unlooping" provides another analogue for the infinity symbol analyzed earlier, which graphically resembles a $\operatorname{loop}^{20}$ (as well as the number 8 , or the number of "parts" Joyce envisioned for the episode, which could be a metaphor for infinity, or the infinite number of "looped" connections between sounds and voices throughout the episode). In this process of looping and unlooping, or noding and disnoding (node: "a junction, a point of intersection or convergence"), Bloom becomes bound to the object in a new sonic configuration, one that produces sounds that he is not master of, despite his attempts to mathematize music: Bloom "loops" and "unloops" along with the elastic band. ${ }^{21}$ Plock argues that the sonic qualities of Bloom's name, with the open "oo" sound, perform the conception of Bloom as a soundboard, as an empty vessel for the resonance of sound: "The letters 'oo' appear as the graphic representation of a hermetically sealed off space or void and make Bloom appear as a hollow, empty vessel receptive for and productive in the transmission of sounds" (Plock 2009, p. 489). Following Plock's logic in this scene, the earlier designation of Bloom as "Bloowho" (11.85) now modulates into "Bloom looped, unlooped", putting him into inter-relation with the sounding action of the band that he is supposed to have been in control of. His attempts to assert mastery over his sonic environment end with him becoming part of this environment, and if he is a "resonating body" in this scene, perhaps we can read him as the resonating body (or "shell") upon which the strings of the lyre are attached and through which they, collaboratively, produce sound. "Binding" here is not a form of protection from the song of the Sirens, but rather a binding to the

20 Another word for the infinity symbol, which only came into usage in the 18th century, is "lemniscate", from the Latin lēminiscus, or "ribbon." "Leminscate", Oxford English Dictionary. Available online: www.library.utoronto.ca (accessed on 15 May 2017).

21 "Node", Oxford English Dictionary. Available online: www.library.utoronto.ca (accessed on 15 May 2017). 
nonhuman sonic universe of the Sirens (as in the "shell" scene from earlier, in which the shell is bound to the hearing ears of George Lidwell, and to those of the barmaids themselves), an assertion of the mutual co-constitution of human and object sonic agency. In this sense, Bloom's weirdly tautological (looped?) statement from the end of the "musemathamatics" passage: "It's on account of the sounds it is", can be read as a way of assigning the sounds themselves some kind of agency in their own expression, and further, would seem to contradict Bloom's earlier focus on the "mathematical" nature of all "music".

\section{Noise without Form}

As an episode that begins with the polyphonic "steelyringing" of horses' hoofs and ends with Bloom's noisy flatulence, "Sirens" is not grounded in harmony, musical or linguistic or otherwise. Like other early 20th-century experimentations in tonality from Schoenberg, Webern, Alban Berg, Béla Bartók, and others, it is, in the most general sense, about breaking the dominant ideal of harmony by embracing the full range of possible sounds instead of privileging a select few dominant ones. The realization that Schoenberg, Webern, Berg, and other adherents of the 12-tone method (or of polymodal chromaticism, in the case of Bartók) came to was that, contrary to musical ideals stemming from Plato and continuing well into the nineteenth century, nature itself was not harmonious. The fiction of harmony, according to Jacques Attali, is imposed upon the cacophony of nature in order to make it seem like the prevailing modes of social order are equivalent to the supposedly "harmonious" laws of nature, and thus beyond critique. Attali writes:

Originally, the idea of harmony was rooted in the idea of order through the endowment of noise with form: "The order of motion is called 'rhythm,' while the order of voice ... is termed 'harmony,' and to the combination of these two the name 'choristy' is given" [Plato, Laws]. Harmony is thus the operator of a compromise between natural forms of noise, of the emergence of a conflictual order, of a code that gives meaning to noise ... Harmony is in a way the representation of an absolute relation between well-being and order in nature. In China as in Greece, harmony implies a system of measurement, in other words, a system for the scientific, quantified representation of nature (Attali 1985, p. 60).

In conversation with Anton Webern, Schoenberg remarked: "Our model in these matters is Nature. Just as in Nature everything develops from the primeval cell, likewise in music, large sound structures should be derived from a single motive which contains the seed of everything that is to come into being" (Wubbolt 1983). However, as discussed above, twelve-tone composition allows for the form to be continually redefined by the motion of its content, by the ceaseless generativity of this "primeval cell" as it continues to grow in unpredictable ways throughout the piece. In this sense, twelve-tone composition (contra Schafer) is not congruous with ideas of the mathematical (Apollonian) conception of music as a reflection of natural harmony, but rather a way of challenging the presumed universality of harmony as both a musical and a natural principle. ${ }^{22}$ The "Sirens" episode, like twelve-tone

22 The question of whether twelve-tone composition reproduces the logic of the domination of nature or whether it provides a way to resist the domination of nature is the subject of the "Musical Domination of Nature" section of Adorno's Philosophy of New Music. The twelve-tone method allows music to become what Adorno calls the "enemy of fate", in that it allows utopian freedom to emerge because it is free from all determinations. However, the twelve-tone method as a way of thinking about freedom and domination can be considered in two ways: first, as another form of mastery and oppression, because now it is the composer who has included every note within the sphere of the composition in a mathematical arrangement: no note goes un-noticed, because the composer is in charge, and can absorb all formerly fugitive elements into the piece, which becomes the image of a bureaucratic, totalitarian society that dominates and controls all of nature. In another sense, however, the twelve-tone method actually relinquishes individual control over the piece: the power lies not with the individual composer, but with the system that controls the individual from outside, through laws not of the composer's own desire or making. In this way, twelve-tone composition resists the logic of domination, of mastery, that enables totalitarian society to emerge. The composer's craft is opened to the laws of nature, laws that emerge from an exterior source, and the piece is made anew each time according to the patterns in which the content arranges itself outside of the control of the composer. See (Adorno 2006, pp. 50-54). 
composition, liberates noise, returning us to the sounding of the shell prior to its sublimation into the laws of harmony via the construction of the lyre, and returning us as well to the guttural sound of the voice ("two tiny silky chords"), the "crying" of Medusa's sisters, prior to its sublimation into the music of the aulos. It also calls for new, inharmonious modes of relation between human and nonhuman sound, relations rooted in the sounding parts of the body and the sounding objects of one's environment to which they are bound.

The famously inharmonious sound that closes the episode is, of course, Bloom's fart. As he ponders the words from the "Speech from the Dock" (1803) of Irish nationalist Robert Emmett before being sentenced to death for treason ("When my country takes her place among the nations of the earth, then and not till then, let my epitaph be written. I have done"), he becomes aware of his stomach rumbling and searches for a convenient time to expel gas, sounding the closing note of the episode:

Prrprr.

Must be the bur.

Fff! Oo. Rrpr.

Nations of the earth. No-one behind. She's passed. Then and not till then. Tram kran kran kran. Good oppor. Coming. Krandlkrankran. I'm sure it's the burgund. Yes. One, two. Let my epitaph be. Kraaaaaa. Written. I have.

Pprrpffrrppffff.

Done. (11.1286-94)

The sounds of Bloom's stomach, as well as his internal monologue, sound in counterpoint with the words of Emmett's speech (as well as the sounds of the nearby tram), culminating in the juxtaposition of two lines: "Pprrpffrrppffff" and "Done". The sound of the fart, as well as its contrapuntal relation to Emmett's words, is given differently in the introduction, where it appears as "Then not till then. My eppripfftaph. Be prfwritt". Again, the sounding of this odd contrapuntal phrase is given multiple times in order to develop its full sonorousness: first, we hear the sounds as they are entangled in one another ("eppripfftaph. Be prfwritt") and second, as they sound when separated into individual phrases (that nonetheless still occur simultaneously). Put another way, we hear them first looped and then unlooped, or noded and then disnoded. Noise is liberated, and allowed to sound alongside the canonical words from Robert Emmet's speech, which is here fragmented into sonic parts, parts that (like the sounding parts of the human body discussed earlier) do not refer back to the unity of a singular subject (or a singular history, a singular nation, in this case), but that reflect the fragmentation of all singular narratives of nation, history, or self. Detached from the frame of a singular body or semantic context, these fragments (of the body, of language) then become allowed to interact with one another to form new sonic articulations such as the counterpoint we experience here.

Shortly prior to this scene, Bloom, prompted by the sound of a blind man tapping his cane on the nearby street, is thinking about how "music" can be found everywhere:

Instruments. A blade of grass, shell of her hands, then blow. Even comb and tissuepaper you can knock a tune out of ... I suppose each kind of trade made its own, don't you see? Hunter with a horn. Haw. Have you the? Cloche. Sonnez la. Shepherd his pipe. Pwee little wee. Policeman a whistle ... It is music. I mean of course it's all pom pom pom very much what they call da capo. Still you can hear. As we march, we march along, march along. Pom. $(11.1237-46)$

Like his earlier attempt to demarcate "noise" from "music", Bloom attempts to locate sonic agency not in the sounds, or "noises", themselves, but in the conscious intentionality that produces "instruments" out of natural and manufactured materials, such as the "blade of grass", the "shell of her hands", "comb and tissuepaper", or "pipe" and "whistle". This is one way to read his use of the phrase "da capo", which is a musical notation indicating that a particular section should be repeated "from the 
beginning". In this sense, all music depends on a particular structure of repetition: the sounds made by each instrument are particular, and they occur in predictable and repeatable patterns: "pom pom pom." However, the literal definition of da capo is "from the head", suggesting that all music, in Bloom's account, emerges from the conscious intention of the composer, who organizes the noises of the world into musical structures.

But this is precisely the line of thinking that Bloom's sonic flatulence, which occurs immediately after this passage, disrupts. This noise proceeds not "from the head", but "from the behind", and occurs not as the result of any conscious intention on the part of its producer, but as the result of the pressures of the body in relation to the food and drink that Bloom has taken into the body ("I'm sure it's the burgund"). Here Bloom becomes a kind of "wind" instrument, ${ }^{23}$ or aulos, a conduit for the expression of the nonhuman entities that have inhered in him (the food he has eaten) and that now expel themselves from his body in the form of gas. ${ }^{24}$ As with the elastic band, Bloom shares sonic agency with the material elements of his world: while he is the one who modulates and times the sound that emerges, he does not fully control the production of the sound nor the precise way in which it sounds. He becomes a kind of resonating soundboard, or a conduit for the sonic expression of his material surroundings that achieve expression through his body. The sound emerges as a co-constituted product of Bloom and his material surroundings (and the materials that he has ingested and put into relation with his body). Like the chamber pot, which resonates in relation to the particular trajectory and force of the liquid being poured into it, Bloom's stomach becomes a resonating body (or "part") that vibrates in particular ways in relation to its surroundings.

The sound of the fart: "Pprrpffrrppffff" also doubles graphically as a series of dynamic indications, alternating as it does between piano $(p)$ and forte $(f)$, and interspersed with the sounds of Bloom's rumbling stomach ("rrr"). In the introduction, as noted by Heath Lees, it is given as "prfwritt", adding the indication ritardando ("to slow down", abbreviated rit) to the more obvious ones of piano and forte (Lees 1984, p. 52). While this particular series of indications would be out of place in a musical composition, here they serve as a way of tracking the alternating growing louder and growing softer of the sound. Additionally, as Schafer notes, the terms piano and forte also designate spatial distinctions between background and foreground. Musical dynamics, according to Schafer, borrow from the analogue of perspective in painting to mark distance and nearness through the loudness and softness of the music. In the "virtual space of [musical] dynamics," according to Schafer, "effects may be brought into the foreground (forte) or allowed to drift back towards the acoustic horizon (piano)" (Schafer 1977, p. 117). Read this way, the closing note of "Sirens" then becomes a noise that oscillates between the background and foreground (piano and forte), troubling the demarcation of sound into the significant foreground (music) and the insignificant background (noise) that Bloom earlier tried to conceptualize. The temptation of the Sirens is to "hear" these background noises (the noises of the sounding parts of the body) and to integrate them into one's sonic world without the hierarchizing move that would deem them unworthy of consideration in comparison to the formalized coding of noises marked by "language" or "music". Considerations of harmony give way to an attentiveness to the precise nature of how objects and bodies (and parts of bodies) sound, and to the rich sonorous particulars of these sounds as they unfold themselves across the horizontal dimension of the page.

But "Sirens" does not end with the sound of Bloom's flatulence. It ends with the single word "Done", the last word of Emmet's speech ("I have done") that resounds alongside the noise of Bloom's flatulence, and that also marks the definitive conclusion of the episode. However, "Done" is also, as Andrew Warren notes, a "percussive" sound that doubles for the noise of Bloom's "basso flatulence" (Warren 2013, p. 663). ${ }^{25}$ Ultimately, it is impossible to place this word/sound, as either an element

23 The motif of the Aeolian harp becomes central here. See footnote 3.

24 Similarly, Stuart Allen argues that "Bloom's transformation into an instrument" in this scene "reveals his inclusion in the material environment of social bodies". See (Allen 2007, p. 455).

25 Warren argues that "Done" also marks the moment of Boylan's orgasm, as imagined by Bloom. 
of semantically meaningful language or a percussive sound emerging from Bloom's body, and this is precisely the point: Done vibrates between language and noise, as both part of Emmet's speech (as read by Bloom) and as a sonic entity unto itself, seemingly detached from any semantic context. In the single sound Done, semantic meaning becomes bound to sonic articulation, language to noise, and human to nonhuman expression. If Sirens are conceived as "ones who bind or entangle", then we can think of the episode as one in which the traditional demarcations between human and nonhuman sound, music and noise, and semantic and sonorous language come unlooped, and sound, or music, becomes a continually unfolding collaboration between human and nonhuman entities (and parts). By unleashing the uncoded noises of the world and liberating them from the sublimating structures of meaning in which they are contained (semantic meaning, the unified human subject, traditional musical forms), "Sirens" suggests new modes of collaborative sonic composition that can only emerge once we obey Lydia's injunction to "Hear!" the multivalent soundings of the nonhumans in our midst.

Conflicts of Interest: The author declares no conflicts of interest.

\section{References}

Adorno, Theodor W. 2006. Philosophy of New Music. Translated by Robert Hullot-Kentor. Minneapolis: University of Minnesota Press.

Allen, Stuart. 2007. "Thinking Strictly Prohibited": Music, Language, and Thought in "Sirens". Twentieth Century Literature 53, no. 4: 442-59. [CrossRef]

Attali, Jacques. 1985. Noise: The Political Economy of Music. Translated by Brian Massumi. Minneapolis: University of Minnesota Press.

Attridge, Derek. 1984. Language as Imitation: Jakobson, Joyce, and the Art of Onomatopoeia. Modern Language Notes 99, no. 5: 1116-40. [CrossRef]

Attridge, Derek. 1986. Joyce's Lipspeech: Syntax and the Subject in "Sirens". In James Joyce: The Centennial Symposium. Edited by Morris Beja, Philip Herring, Maurice Harmon and David Norris. Urbana: University of Illinois Press.

Bénéjam, Valérie. 2011. The Acoustic Space of Ulysses. In Making Space in Ulysses. Edited by John Bishop and Valérie Bénéjam. New York: Routledge, pp. 63-64.

Brown, Susan. 2007. The Mystery of the Fuga per Canonem Solved. Genetic Joyce Studies. Available online: http:/ / www.geneticjoycestudies.org/GJS7/GJS7brown.html (accessed on 25 May 2017).

Ellmann, Richard. 1982. James Joyce. Oxford: Oxford University Press.

Epstein, Josh. 2011. Joyce's Phoneygraphs: Music, Mediation, and Noise Unleashed. James Joyce Quarterly 48, no. 2: 265-89. [CrossRef]

Ferrer, Daniel. 2001. What Song the Sirens Sang ... Is No Longer beyond All Conjecture: A Preliminary Description of the New "Proteus" and "Sirens" Manuscripts. James Joyce Quarterly 39, no. 1: 53-68. [CrossRef]

Herman, David J. 1994. “Sirens" After Schoenberg. James Joyce Quarterly 31, no. 4: 473-94.

Homer, Bernard Knox. 1986. The Odyssey. Translated by Robert Fagles. New York: Penguin, pp. $276-77$.

Joyce, James. 1975. Selected Letters. Edited by Richard Ellmann. New York: Viking, p. 242.

Dubliners Joyce, ed. 2006. Margot Norris. New York: Norton.

Knowles, Sebastian. 1986. The Substructure of "Sirens": Molly as Nexus Omnia Ligans. James Joyce Quarterly 23, no. 4: 447-63.

Lawrence, Karen. 1981. The Odyssey of Style in Ulysses. Princeton: Princeton University Press, p. 94.

Lees, Heath. 1984. The Introduction to 'Sirens' and the "Fuga per Canonem". James Joyce Quarterly 22, no. 1: 39-54.

Levin, Lawrence L. 1965. The Sirens Episode as Music: Joyce's Experiment in Prose Polyphony. James Joyce Quarterly 3, no. 1: 12-24.

Martin, Timothy. 2000-2001. Operatic Joyce. James Joyce Quarterly 38, no. 1-2: 25-43.

Nietzsche, Friedrich. 1968. On Truth and Lie in an Extra-Moral Sense. In The Portable Nietzsche. Translated by Walter Kaufmann. New York: Viking, p. 45.

Ordway, Scott. 2007. A Dominant Boylan: Music, Meaning, and the Sonata Form in "Sirens". James Joyce Quarterly 45, no. 1: 85-96. 
Plock, Vike Martina. 2009. Good Vibrations: “Sirens", Soundscapes, and Physiology. James Joyce Quarterly 46, no. 3-4: 481-96.

Rath, Richard Cullen. 2012. No Corner for the Devil to Hide. In The Sound Studies Reader. Edited by Jonathan Sterne. New York: Routledge.

Schafer, R. Murray. 1977. The Soundscape: Our Sonic Environment and the Tuning of the World. Rochester: Destiny Books. Schoenberg, Arnold. 1975. Composition with Twelve Tones (I). In Style and Idea: Selected Writings of Arnold Schoenberg. Edited by Leonard Stein. Translated by Leo Black. Berkeley: University of California Press.

Serres, Michel. 2016. The Five Senses. Translated by Margaret Sankey, and Peter Cowley. London: Bloomsbury.

Warren, Andrew. 2013. How to Listen to "Sirens": Narrative Distraction at the Ormond Hotel. James Joyce Quarterly 50, no. 3: 655-74. [CrossRef]

Webern, Anton. 1963. The Path to the New Music. Edited by Willi Reich. Translated by Leo Black. Bryn Mawr: Theodore Presser Company, p. 11.

Witen, Michelle. 2010. The Mystery of the Fuga per Canonem Reopened? Genetic Joyce Studies. Issue 10. Available online: http:/ / www.geneticjoycestudies.org/GJS10/GJS10_MichelleWiten.htm (accessed on 25 May 2017).

Witen, Michelle. 2018. Joyce and Absolute Music. London: Bloomsbury Press.

Wubbolt, Georg. 1983. Weberns Goethe-Rezeption. In Opus Anton Webern. Edited by Dieter Rexroth. Berlin: Quadranga, p. 107.

Zimmerman, Nadya. 2002. Musical Form as Narrator: The Fugue of the Sirens in James Joyce's Ulysses. Journal of Modern Literature 26, no. 1: 108-18. [CrossRef]

(C) 2017 by the author. Licensee MDPI, Basel, Switzerland. This article is an open access article distributed under the terms and conditions of the Creative Commons Attribution (CC BY) license (http:/ / creativecommons.org/licenses/by/4.0/). 